\title{
Investigate the mechanisms of Chinese medicine Fuzhengkangai towards EGFR mutation-positive lung adenocarcinomas by network pharmacology
}

Zhitong Bing ${ }^{1,2,3+}$, Zhiyuan Cheng ${ }^{1,2+}$, Danfeng Shi ${ }^{4 \dagger}$, Xinkui Liu ${ }^{5}$, Jinhui Tian ${ }^{1,2}$, Xiaojun Yao ${ }^{4}$, Jingyun Zhang ${ }^{1,2}$, Yongfeng Wang ${ }^{6}$ and Kehu Yang ${ }^{1,2^{*}}$

\begin{abstract}
Background: Chinese traditional herbal medicine Fuzhengkangai (FZKA) formulation combination with gefitinib can overcome drug resistance and improve the prognosis of lung adenocarcinoma patients. However, the pharmacological and molecular mechanisms underlying the active ingredients, potential targets, and overcome drug resistance of the drug are still unclear. Therefore, it is necessary to explore the molecular mechanism of FZKA.

Methods: A systems pharmacology and bioinformatics-based approach was employed to investigate the molecular pathogenesis of EGFR-TKI resistance with clinically effective herb formula. The differential gene expressions between EGFR-TKI sensitive and resistance cell lines were calculated and used to find overlap from targets as core targets. The prognosis of core targets was validated from the cancer genome atlas (TCGA) database by Cox regression. Kyoto Encyclopedia of Genes and Genomes (KEGG) pathway enrichment is applied to analysis core targets for revealing mechanism in biology.

Results: The results showed that 35 active compounds of FZKA can interact with eight core targets proteins (ADRB2, BCL2, CDKN1A, HTR2C, KCNMA1, PLA2G4A, PRKCA and LYZ). The risk score of them were associated with overall survival and relapse free time ( $\mathrm{HR}=6.604,95 \% \mathrm{Cl}: 2.314-18.850 ; \mathrm{HR}=5.132,95 \% \mathrm{Cl}: 1.531-17.220)$. The pathway enrichment suggested that they involved in EGFR-TKI resistance and non-small cell lung cancer pathways, which directly affect EGFR-TKI resistance. The molecular docking showed that licochalcone a and beta-sitosterol can closely bind two targets (BCL2 and PRKCA) that involved in EGFR-TKI resistance pathway.
\end{abstract}

Conclusions: This study provided a workflow for understanding mechanism of CHM for against drug resistance.

Keywords: Systems pharmacology, Fuzhengkangai formula, Herbal medicines, Molecular docking

\section{Background}

Lung cancer is a leading cause of cancer mortality worldwide, more than $85 \%$ of which is non-small cell lung cancer (NSCLC). Lung adenocarcinoma is the major form of NSCLC, which represents about $50 \%$ of

\footnotetext{
*Correspondence: kehuyangebm2006@126.com

'Zhitong Bing, Cheng Zhiyuan and Danfeng Shi contributed equally to this work.

${ }^{1}$ Evidence Based Medicine Center, School of Basic Medical Science of Lanzhou University, Lanzhou, China

${ }^{2}$ Key Laboratory of Evidence Based Medicine and Knowledge Translation of Gansu Province, 199 West Donggang Road, Lanzhou 730000, Gansu, China Full list of author information is available at the end of the article
}

lung cancer [1]. Epidermal growth factor receptor (EGFR) mutation is a main contributing factor of lung adenocarcinoma (LUAD) in east Asian countries (about $60 \%$ of lung adenocarcinoma) [2]. In China, according to cancer statistics for 2015, lung cancer shows the highest morbidity and mortality [3].

The epidermal growth factor receptor tyrosine kinase inhibitors (EGFR-TKIs) such as gefitinib, erlotinib and afatinib, which targeted the EGFR pathway, showed potential in the treatment of patients with EGFR mutated NSCLC [4]. And the drugs have effects on LUAD patients with EGFR mutations including the deletion of

(c) The Author(s). 2018 Open Access This article is distributed under the terms of the Creative Commons Attribution 4.0 International License (http://creativecommons.org/licenses/by/4.0/), which permits unrestricted use, distribution, and reproduction in any medium, provided you give appropriate credit to the original author(s) and the source, provide a link to the Creative Commons license, and indicate if changes were made. The Creative Commons Public Domain Dedication waiver (http://creativecommons.org/publicdomain/zero/1.0/) applies to the data made available in this article, unless otherwise stated. 
exon 19 and L858R missense mutation of exon 21 [5]. Although they are effective for early treatment of LUAD, patients will soon have drug resistance in 4 to 12 months during therapy process [2]. Researchers have made great efforts to explore resistance mechanisms and they have discovered many mechanisms of EGFR-TKI resistance. The most frequently studied mechanism of acquired resistance is the T790 $\mathrm{M}$ point mutation in exon 2 of EGFR [6, 7]. Secondly, in histologic transformation, the small cell of LUAD histologic transformation and epithelial-mesenchymal transition (MET) activation were closely associated with the acquired EGFR-TKI resistance in patients with never smoked [8-11]. MET and HER2 amplification are also reported to associate with EGFR-TKI resistance [12-14]. BRAF secondary mutations have also been implicated to EGFR-TKI resistance [15]. In recent studies, PAK1 activation, upregulation of BCL2, elevation of CDKN1A (p21), overexpression of PHGDH and IGF1R related with acquire resistance [2, 16-19]. To sum up, so many mechanisms of drug resistance are very harmful to the target treatment of patients. How to overcome various anti-drug mechanisms is the focus of attention of many scientists.

Previous studies reported that Chinese Herbal Medicine (CHM) Fuzhengkangai (FZKA) formulation has a good performance in clinical cancer treatment [20, 21]. In recent year, Yang et al. reported that CHM of FZKA combine gefitinib had great effect to treat lung adenocarcinoma with EGFR mutation patients [22]. The study indicates that CHM combination of gefitinib can improve relapse free survival (RFS) significantly. However, the mechanism of CHM in LUAD remain unclear. With the deepening of network pharmacology research, an increasing number of the mechanism of CHM has been revealed [23-25]. Thus, this study employed network pharmacology, bioinformatics and molecular docking method to investigate the molecular mechanism of FZKA in against drug resistance.

\section{Methods}

\section{Composite of Chinese herbs of FZKA}

Previous publication has reported the composition of FZKA [22]. This prescription involved eleven herbs which contained Atractylodes Macrocephala Koidz (Baizhu), Hedyotis Diffusae Herba (Baihuasheshecao), Curcumae Rhizoma (ezhu), Licorice (Gancao), Hedysarum multijugum Maxim (Huangqi), Solanum nigrum Linn (Longkui), Pseudobulbus Cremastrae Seu Pleiones (Shancigu), Salviae Chinensis Herba (Shijianchuan), Pseudostellariae Radix (Taizishen), Tetrapanacis Medulla (Tongcao) and Coicis Semen (Yiyiren).

The information of molecular target filtering was employed to Traditional Chinese Medicines for Systems
Pharmacology Database and Analysis Platform (TCMSP, http://lsp.nwsuaf.edu.cn/tcmsp.php) [26].

\section{Pharmacokinetic prediction}

The properties of absorption, distribution, metabolism and excretion (ADME) were considered as important indicators for effectiveness in herbs. According to publications, three ADME-related models, including the evaluation of oral bioavailability (OB), Caco-2 permeability and drug-likeness (DL), are applied to identify the potential bioactive compound of FZKA. Each of property in above was illustrated as following:

OB represents fraction of the oral dose of bioactive compound which reaches systemic circulation in the TCM remedy. The reasonable threshold of $\mathrm{OB}$ was set to $33 \%$ for further analysis. And the threshold of $\mathrm{OB}$ referred to previous studies and used their criterion [27-30]. The indicator of Caco-2 widely applied as standard permeability-screening assay for prediction of the compound's intestinal absorption and fraction of oral dose absorbed in humans. In this study, the threshold of Caco-2 permeability was set to 0.4 [31]. Drug-likeness evaluation is used in drug design to evaluation whether a compound is chemically suitable for drug, and how drug-like a molecule is with respect to parameters affecting its pharmacodynamic and pharmacokinetic profiles which ultimately impact its ADME properties. In this study, the threshold of DL was set to 0.18 [32].

\section{Differential expression genes between sensitive and resistance EGFR-TKI lung cancer cells}

The differential expression genes (DEGs) between EGFR-TKI sensitive and resistance were calculated from public dataset of Gene Expression Omnibus (GEO). GSE34228 dataset include gefitinib sensitive $(n=26)$ and resistance $(n=26)$ PC9 cell lines. For assay the deregulation gene expression, "limma" package of $\mathrm{R}$ software was employed to test the DEGs. mRNAs with $\log _{2}$ fold change $|\log \mathrm{FC}| \geq 1$ (FDR adjusted $P<0.01$ ) were considered to be differentially expressed mRNAs.

\section{Identify core sub-network from compound-target network}

For identifying core targets from compounds-targets network, the overlap of DEGs and targets were extracted. There eight overlap targets were identified. We selected eight targets and their neighbors (only compounds) as core sub-network.

\section{Validation compound-target interaction via docking simulation}

Molecular docking simulation was performed to validate those interactions and guide the associated drug 
discovery in the Glide module of Schrödinger software (Version, Schrödinger, Inc., New York, NY, 2015). The studied compounds were prepared and optimized in the LigPrep module. The crystal structures of the studied protein targets were derived from the protein data bank (PDB) database (http://www.rcsb.org/) and prepared using the Protein Preparation Wizard. The centroid of the co-crystalized inhibitor in the crystal structures of complex was defined as the binding site. The poses of the studied compounds are evaluated by both standard precision and extra precision (XP) docking score and the binding conformation with the highest score was selected for binding mode analysis.

\section{Validation in cohort with EGFR mutation}

The gene expression, samples with EGFR mutation and clinical information of lung adenocarcinoma (LUAD) were downloaded from TCGA database (https://portal.gdc.cancer.gov/). For filtering EGFR mutation samples, we selected the samples which both contain EGFR mutation and complete follow-up information (overall survival). After filtering the samples, there are forty-five samples were included for further analysis. In addition, the patients with relapse free survival (RFS) time information were also selected to validate. There were thirty-seven patients with RFS were filtered to test.

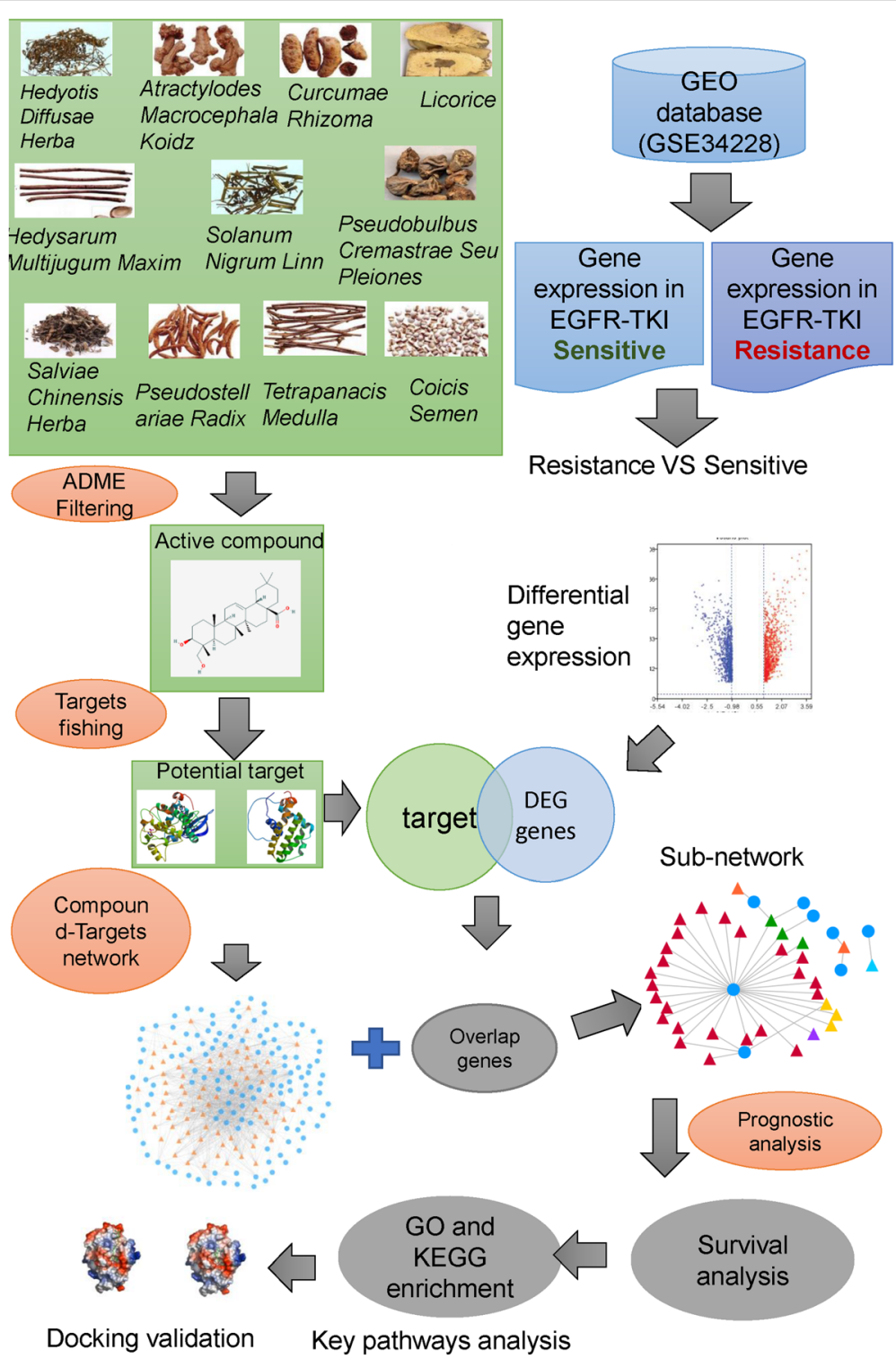

Fig. 1 Flowchart of data analysis 


\section{Risk sore construction}

A risk score (RS), linear combination of candidate mRNAs (targets of active compounds) for each LUAD patient with EGFR mutation $(n=45)$, is constructed. The RS was calculated from sum of the expression value of the mRNAs weight multiplied by univariate Cox regression coefficients.

$$
\text { Risk score }(\mathrm{RS})=\sum_{i} V_{i} \times \beta_{i}
$$

where $\beta_{i}$ represents the Cox regression coefficient of the $i$ th variable, and $V_{i}$ represents the value of the ith variable. Where $V_{i}$ is the $\log 2$-transformed expression value of every mRNA and $\beta_{i}$ is the univariate Cox proportional hazards regression coefficient of the $i$ th mRNA.

\section{Survival analysis and receiver operating characteristic curves} The prognostic performance was measured using the area under the curve (AUC) derived from time-dependent receiver operating characteristic (ROC) analysis, and the accuracy of the risk score to predict overall survival (OS) at 3 years was assessed. And risk score to predict RFS at 3 years was also tested. The capacity of the model was evaluated by analysis of area under curve
(AUC) of the receiver operating characteristic (ROC) curves. Generally, the value of AUC is between 0.5 and 1, and the larger AUC represents a better performance. The value of AUC is greater than 0.7. It is considered that the model has good capacity in classification. The risk of patient group was classified into two groups (a sensitive and a resistance group) according to median value point of individual patient RS. All statistical analyses were conducted using $R$ Software (Version 3.4.2). Survival curves and ROC curves were generated by the 'survminer' [33], 'survival', and 'survivalROC' packages [34].

\section{Network visualization and KEGG enrichment}

The networks were constructed by Cytoscape software version 3.6.1, which is an open source software for network visualization and analysis [35]. In the network, the compounds and targets are showed by nodes, and the interaction between two nodes is represented by an edge. KEGG analysis were carried out using clusterProfiler package in R (v3.4.2) [36]. KEGG pathways visualization was employed to CyKEGGParser application (Version 1.2.9) in Cytoscape software.

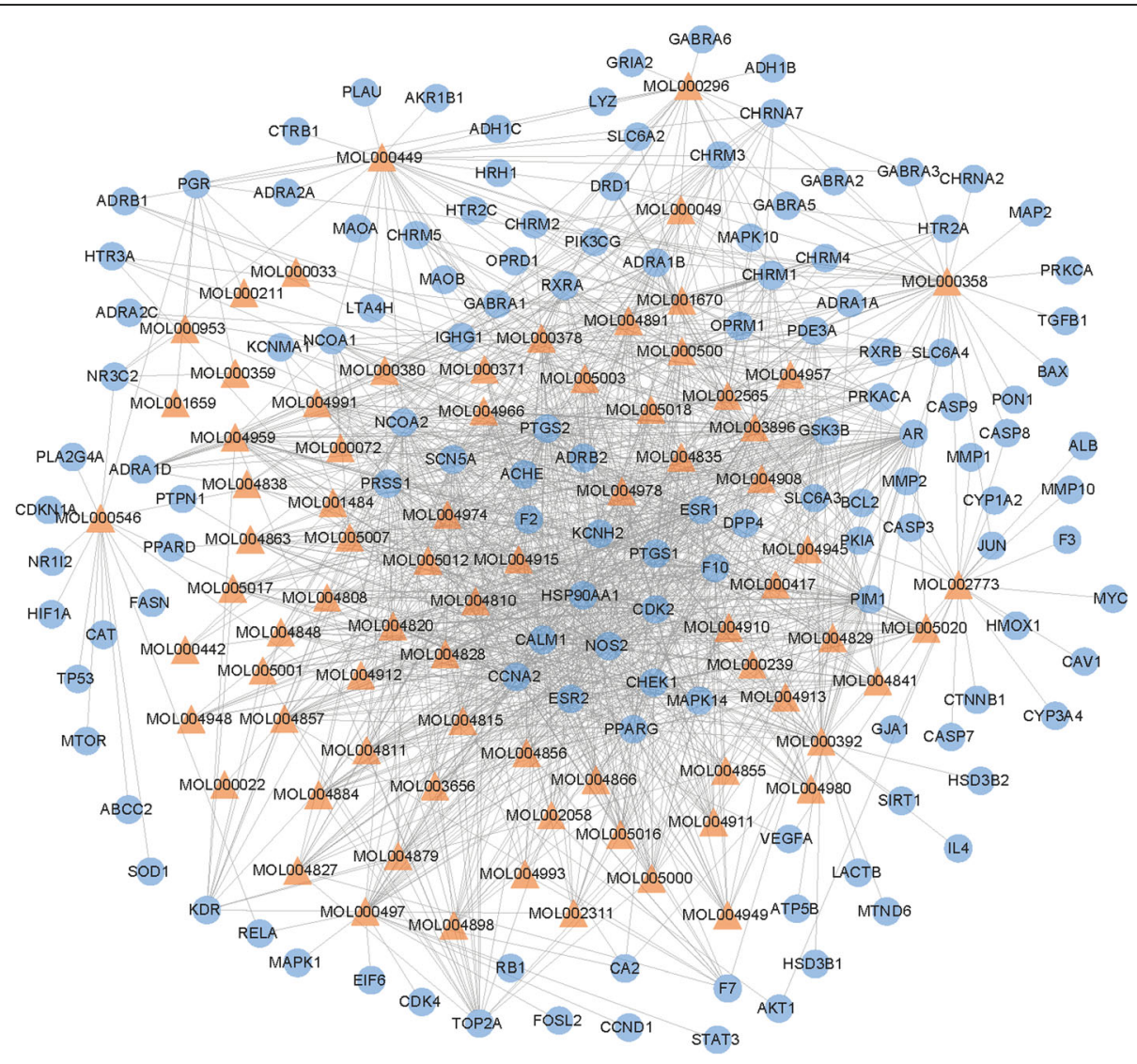

Fig. 2 A compound node and a protein node are linked if the protein is targeted by the corresponding compound. Node size is proportional to its degree 


\section{Results}

\section{Design of workflow}

For investigating the mechanism of FZKA in EGFR-TKI resistance in molecular level, a hypothesis was proposed, which assumes that targets of bioactive compounds may involve in some pathways that against the EGFR-TKI. In addition, the overlap of targets and DEGs between resistance and sensitive EGFR-TKI NSCLC cell lines would be core targets of herbs. Generally, LUAD patients with sensitive for EGFR-TKI would have better prognosis than resistance. Thus, the prognosis of overlap was validated in LUAD patients with EGFR mutation form TCGA database. For further analysis the pathway of targets, KEGG pathway analysis was used to investigate the active pathway which involved in EGFR-TKI resistance. Finally, molecular docking simulation was employed to validate the interaction of compound and target. The docking simulation can explain the mechanism of interaction how to affect the pathway (Fig. 1).

\section{Active compounds filtering}

After filtering by criterion of ADME in method, a total of 76 compounds were filtered from the eleven herbs of FZKA (Additional file 1). From TCMSP database, the compound-target network was constructed from 76 compounds and 130 targets (Additional file 2). And the network was showed as following (Fig. 2).

The complex network suggested each compound could affect many targets, which can regulate those targets to affect biological process. Although the network showed compound-target interaction, the mechanism in EGFR-TKI resistance LUAD cells was difficult to understand. Thus, the DEGs of sensitive and resistance in LUAD were calculated for further investigation mechanism of herbs.

\section{Genes associated with Gefitinib resistance}

Gefitinib sensitive and resistance cell lines were collected from GSE34228. After filtering by some criterions as methods, there were 449 up-regulation genes and 531 down-regulation genes (Fig. 3a, b). The pathway enrichment of DEGs was employed to KEGG (Fig. 3c).

The volcano plot and heatmap showed fold-changes and DEGs in two groups. KEGG enrichment suggested that down-regulated genes involved in more pathways. Of these pathways, some pathways were closely associated with cancer development such as Jak-STAT signaling pathway, TNF signaling pathway, Ras signaling pathway and ErbB signaling pathway. For investigating more accurate targets of FZKA, we intersected the differentially expressed genes and drug targets.

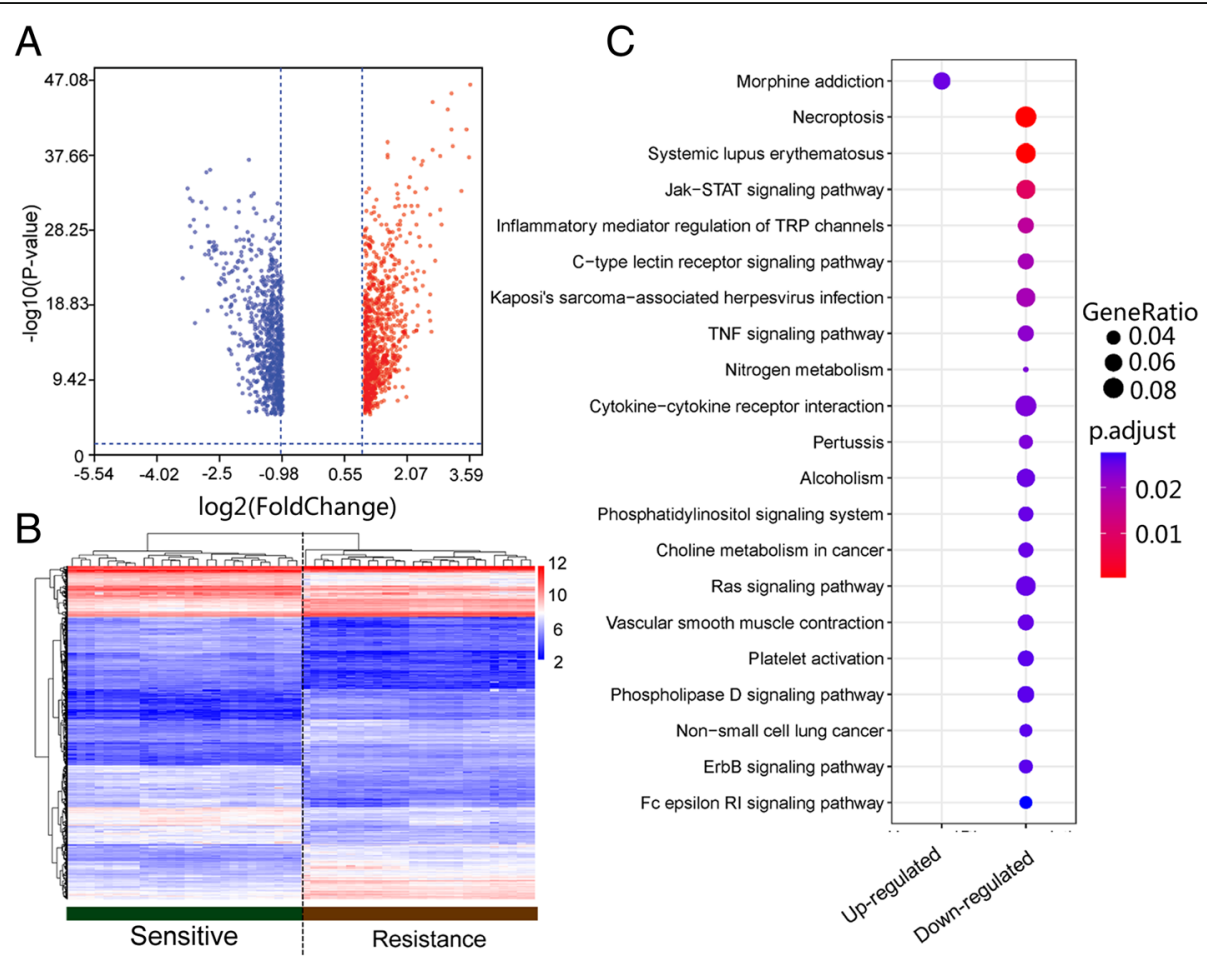

Fig. 3 The information of DEGs and pathway of DEGs. a Volcano plot represents DEGs. b Heatmap of DEGs between sensitive and resistance groups. c KEGG enrichment of DEGs 
Table 1 Information of active compound by ADME filtering

\begin{tabular}{lllllll}
\hline $\mathrm{ID}$ & compounds & $\mathrm{OB}$ & Caco.2 DL Herbs \\
\hline MOL000049 & $3 \beta$-acetoxyatractylone & 54.07 1.13 0.22 Atractylodes \\
Macrocephala Koidz.
\end{tabular}

MOL000296 hederagenin<smiles>CC[C@H](CC[C@@H](C)[C@H]1CC[C@H]2[C@@H]3CC=C4C[C@@H](O)CC[C@]4(C)[C@H]3CC[C@@]21C)C(C)C</smiles>

$36.91 \quad 1.32 \quad 0.75$ Curcumae Rhizoma

MOL000358 beta-sitosterol

MOL000371 3,9-di-O-methylnissolin

MOL000380 (6aR,11aR)-9,10-dimethoxy-6a,11a-dihydro-6Hbenzofurano[3,2-c]chromen-3-ol

MOL000392 Formononetin

MOL000417 Calycosin

MOL000449 Stigmasterol<smiles>CC[C@H](CC[C@@H](C)[C@H]1CC[C@H]2[C@@H]3CC=C4C[C@@H](O)CC[C@]4(C)[C@H]3CC[C@@]21C)C(C)C</smiles><smiles>COc1ccc2c(c1)OC[C@H]1c3ccc(OC)c(OC)c3O[C@H]21</smiles>

$53.74 \quad 1.18 \quad 0.48$ Hedysarum multijugum Maxim.

74.691 .08<smiles>COc1ccc2c(c1)OC[C@H](c1ccc(OC)c(OC)c1O)C2</smiles>

$\begin{array}{lll}36.91 & 1.32 \quad 0.75 & \begin{array}{l}\text { Hedyotis Diffusae } \\ \text { Herba }\end{array}\end{array}$

0.3 Hedysarum Multijugum Maxim.<smiles>COc1ccc2c(c1OC)O[C@H]1c3ccc(O)cc3OC[C@H]21</smiles>

$64.26 \quad 0.93$

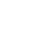

\footnotetext{
$\begin{array}{llll}69.67 & 0.78 & 0.21 & \text { licorice }\end{array}$
}

$\mathrm{HO}$<smiles>COc1ccc(-c2coc3cc(C)ccc3c2=O)cc1</smiles>

$\mathrm{HO}$<smiles>COc1ccc(-c2coc3cc(C)ccc3c2=O)cc1O</smiles>

$\begin{array}{llll}47.75 & 0.52 & 0.24 & \text { licorice }\end{array}$<smiles>CC[C@H](/C=C/[C@H](C)[C@H]1CC[C@H]2[C@@H]3CC=C4C[C@@H](O)CC[C@]4(C)[C@H]3CC[C@@]21C)C(C)C</smiles> 
Table 1 Information of active compound by ADME filtering (Continued)

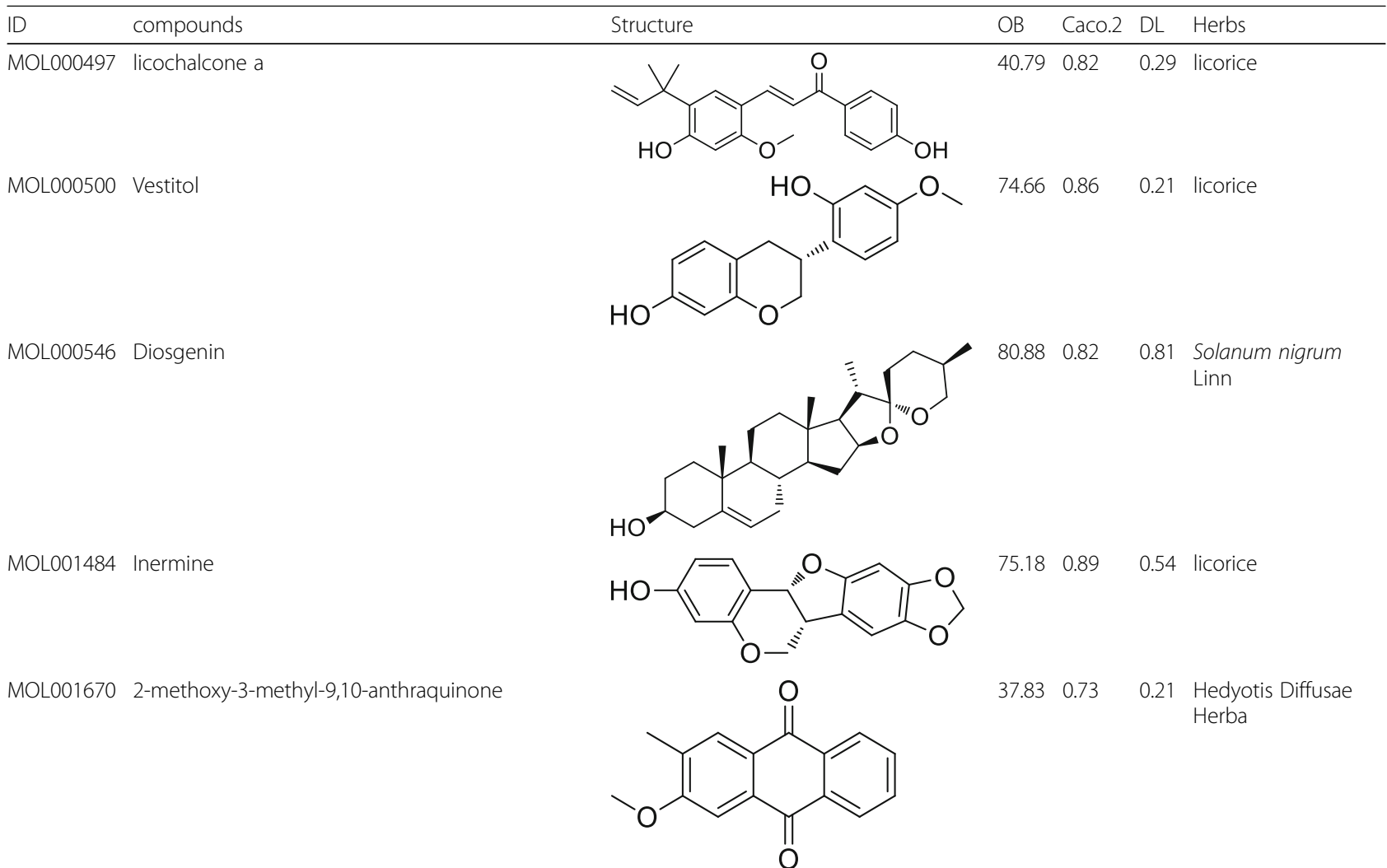

MOL002565 Medicarpin<smiles>COc1ccc2c(c1)O[C@H]1c3ccc(O)cc3OC[C@H]21</smiles>

$49.22 \quad 1 \quad 0.34$ licorice

MOL002773 beta-carotene

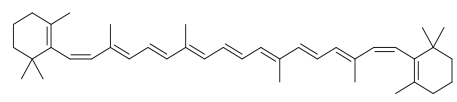

$\begin{array}{llll}37.18 & 2.25 & 0.58 & \text { Solanum Nigrum }\end{array}$ Linn<smiles>COc1ccc(-c2coc3cc(O)c(CC=C(C)C)c(O)c3c2=O)cc1O</smiles>

MOL003896 7-Methoxy-2-methyl isoflavone<smiles>COc1ccc2c(=O)c(-c3ccccc3)c(C)oc2c1</smiles>

MOL004835 Glypallichalcone<smiles>COc1ccc(C(=O)/C=C/c2ccc(O)cc2OC)cc1</smiles>

MOL004841 Licochalcone B<smiles>COc1c(/C=C/C(=O)c2ccc(O)cc2)ccc(O)c1O</smiles>

$\begin{array}{llll}76.76 & 0.47 & 0.19 & \text { licorice }\end{array}$

$48.79 \quad 0.58$ 0.45 licorice

\section{$\begin{array}{llll}42.56 & 1.16 & 0.2 & \text { licorice }\end{array}$}

$\begin{array}{llll}61.6 & 0.76 & 0.19 & \text { licorice }\end{array}$

MOL004857 Gancaonin B 
Table 1 Information of active compound by ADME filtering (Continued)

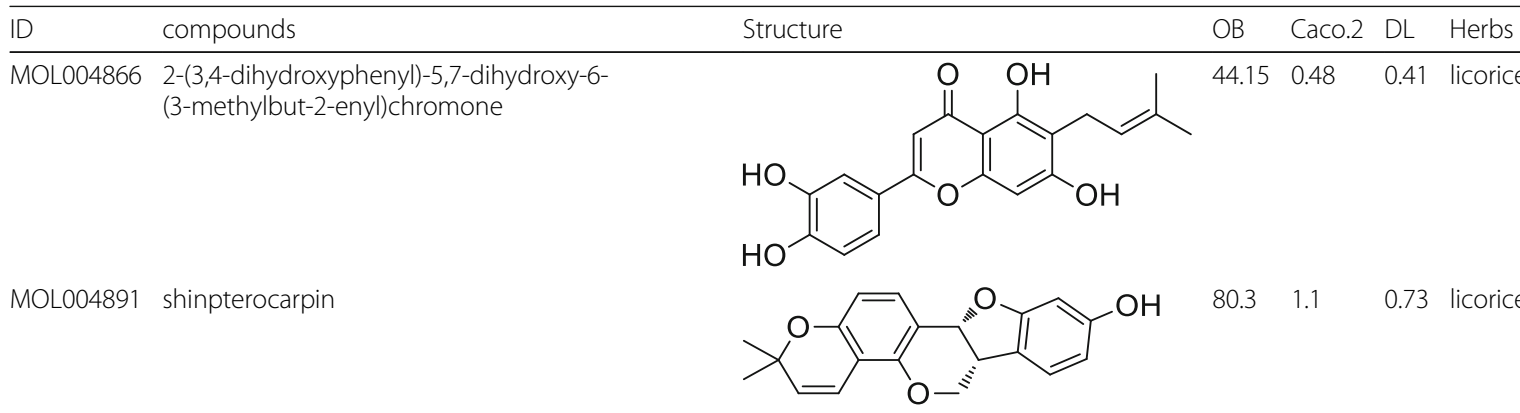

MOL004908 Glabridin<smiles>CC1(C)C=Cc2c(ccc3c2OC[C@@H](c2ccc(O)cc2O)C3)O1</smiles>

MOL004911 Glabrene<smiles>CC1(C)C=Cc2c(O)ccc(C3=Cc4ccc(O)cc4OC3)c2O1</smiles>

$\begin{array}{lll}46.27 & 0.99 & 0.44 \\ \text { licorice }\end{array}$

MOL004945 (25)-7-hydroxy-2-(4-hydroxyphenyl)-8-(3-
methylbut-2-enyl) chroman-4-one

MOL004945 (2S)-7-hydroxy-2-(4-hydroxyphenyl)-8-
methylbut-2-enyl) chroman-4-one<smiles>CC(C)=CCc1c(O)ccc2c1O[C@H](c1ccc(O)cc1)CC2=O</smiles>

$\begin{array}{llll}36.57 & 0.72 & 0.32 & \text { licorice }\end{array}$<smiles>COc1ccc2c(=O)c(-c3ccc(O)cc3)coc2c1</smiles>

MOL004959 1-Methoxyphaseollidin<smiles>COc1cc(O)cc2c1[C@H]1OC[C@@H]2c2ccc(O)c(CC=C(C)C)c2O1</smiles>

$\begin{array}{llll}69.98 & 1.01 & 0.64 & \text { licorice }\end{array}$

MOL004966 3'-Hydroxy-4'-O-Methylglabridin<smiles>COc1ccc(C2COc3c(ccc4c3C=CC(C)(C)O4)C2)c(O)c1O</smiles>

$\begin{array}{lll}38.37 & 0.79 & 0.21\end{array}$ licorice<smiles>CCOCCOCCOCCOCCO</smiles>

$43.71 \quad 1$ 0.57 licorice

MOL004974 3'-Methoxyglabridin<smiles>COc1c(O)ccc([C@H]2COc3c(ccc4c3C=CC(C)(C)O4)C2)c1O</smiles>

$46.16 \quad 0.94$

0.57 licorice

MOL004978 2-[(3R)-8,8-dimethyl-3,4-dihydro-2H-pyrano[6,5f]chromen-3-yl]-5-methoxyphenol<smiles>COc1ccc([C@H]2COc3c(ccc4c3C=CC(C)(C)O4)C2)c(O)c1</smiles> 
Table 1 Information of active compound by ADME filtering (Continued)

\begin{tabular}{|c|c|c|c|c|c|c|}
\hline $\mathrm{ID}$ & compounds & Structure & $\mathrm{OB}$ & Caco.2 & $\mathrm{DL}$ & Herbs \\
\hline MOL004980 & Inflacoumarin A & & 39.71 & 0.73 & 0.33 & licorice \\
\hline MOL004991 & 7-Acetoxy-2-methylisoflavone & & 38.92 & 0.74 & 0.26 & licorice \\
\hline MOL005003 & Licoagrocarpin & & 58.81 & 1.23 & 0.58 & licorice \\
\hline MOL005007 & Glyasperins M & & 72.67 & 0.49 & 0.59 & licorice \\
\hline MOL005020 & dehydroglyasperins $C$ & & 53.82 & 0.68 & 0.37 & licorice \\
\hline
\end{tabular}

\section{Core genes identification and network analysis}

For identification some core genes in EGFR-TKI resistance of NSCLC, the overlapping genes between targets and DEGs were identified. Eight overlap genes and thirty-five compounds were identified (Tables 1 and 2). The expression of core genes and subnetwork of compound-target network were showed in Fig. 4.

The results showed that 35 compounds acted on 20 pathways, which showed average degree of 6.32. In the compound-pathway network, the compounds mainly involved in pathways such as Salivary secretion (degree $=33$ ),
Renin secretion $($ degree $=32)$ and Calcium signaling pathway (degree $=31$ ) (Additional file 3 ).

As shown in Fig. 4d, we clustered the pathways into four modules which were secretion pathways, drug resistance pathways, cancer pathways and signaling pathways. The compounds of FZKA have multiple target effects and involved in multiple pathways that may be related to drug resistance. Of these compounds, MOL000497 (licochalcone a), MOL002773 (beta-carotene), MOL000358 (beta-sitosterol) and MOL000546 (diosgenin) directly involved in drug resistance

Table 2 Core targets of Fuzhengkangai

\begin{tabular}{llllc}
\hline Uniprot accession & Gene names & Protein name & Log (Fold Change) & Adjust $P$ value \\
\hline P07550 & ADRB2 & Beta-2 adrenergic receptor & 1.02 & $1.63 \mathrm{e}-17$ \\
P10415 & BCL2 & Apoptosis regulator BCl-2 & 1.20 & $1.49 \mathrm{e}-9$ \\
P38936 & CDKN1A & Cyclin-dependent kinase inhibitor 1 & -1.01 & $4.79 \mathrm{e}-12$ \\
P28335 & HTR2C & 5-hydroxytryptamine receptor 2C & 1.21 & $2.58 \mathrm{e}-16$ \\
Q12791 & KCNMA1 & Calcium-activated potassium channel subunit alpha-1 & 1.01 & $1.70 \mathrm{e}-8$ \\
P47712 & PLA2G4A & Cytosolic phospholipase A2 & -1.33 & $3.70 \mathrm{e}-8$ \\
P17252 & PRKCA & Protein kinase C alpha type & 1.06 & $3.69 \mathrm{e}-13$ \\
P61626 & LYZ & Lysozyme C & 1.91 & $4.52 \mathrm{e}-17$ \\
\hline
\end{tabular}




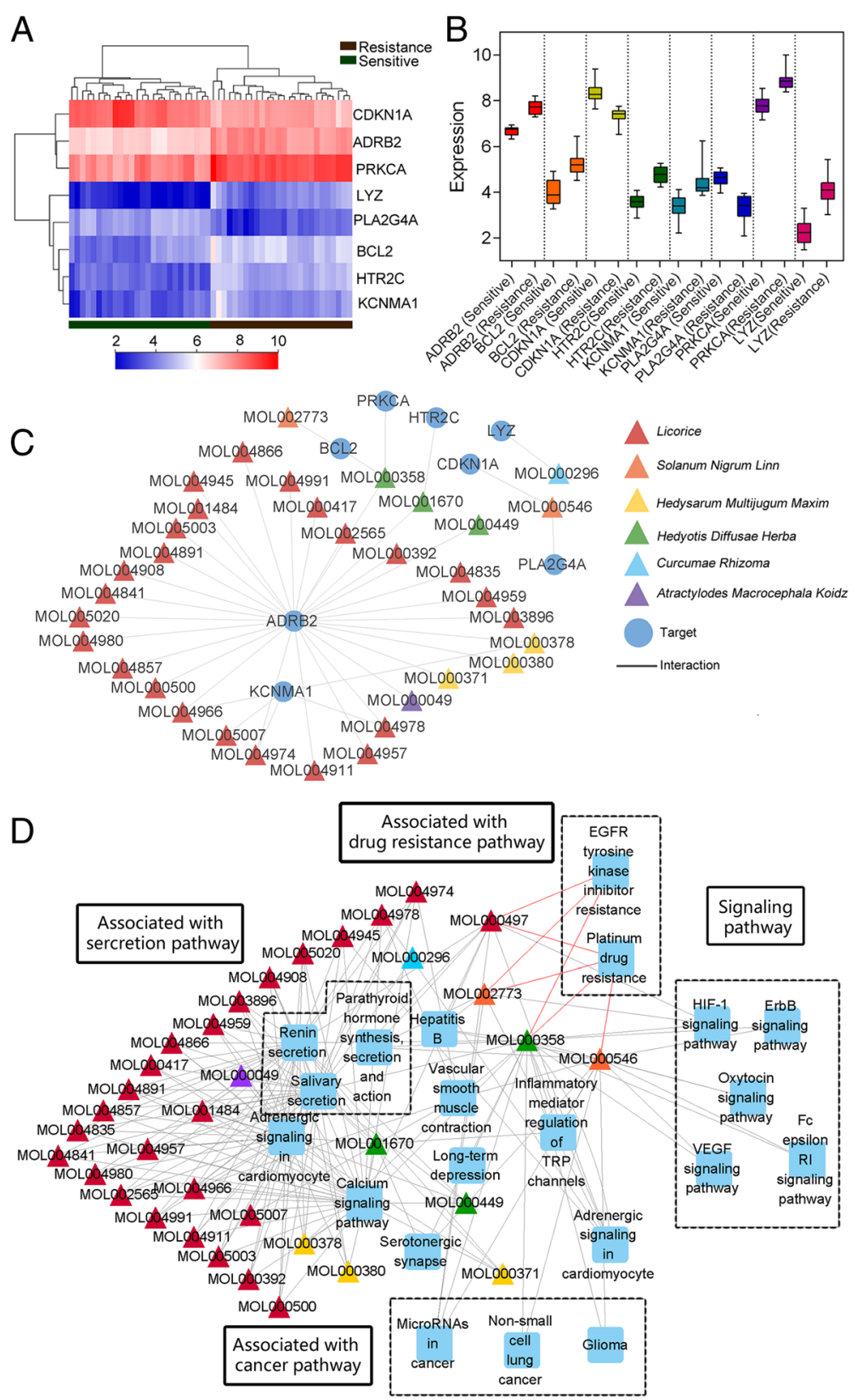

Fig. 4 Expression of core genes and subnetwork of core genes. a Heatmap of core genes in EGFR-TKI resistance and sensitive groups. $\mathbf{b}$ boxplot of each core gene between two groups. c Subnetwork of compounds and targets. The triangles represent different compounds and different color represent herbs that include the compounds. $\mathbf{d}$ The compound-pathway interaction network is constructed by compound and the pathway that consisted of core targets. Red lines represent compounds directly related to drug resistance

pathways (EGFR-TKI resistance and platinum drug resistance).

\section{Core genes validation in independent dataset}

The core genes were searched from EGFR-mutation LUAD cohort in TCGA. The clinical factors and baseline information of these patients were listed in Table 3. And RS of overall survival is calculated from linear combination of gene expression and coefficient. The median value of RS is considered as threshold to classify patients into two groups and RS was significantly associated with LUAD patient survival $(\mathrm{HR}=6.604,95 \% \mathrm{CI}$ : $2.314-$ 18.850). Generally, sensitive group would have longer survival time than resistance. The median value of RS showed that survival of sensitive group was significantly better than resistance group $(p=0.0012)$ (Fig. 5a). The RS distribution in patients was showed in Fig. 5b. And AUC of RS showed that the core genes model performed 
Table 3 Baseline information of NSCLC patients with EGFR mutation

\begin{tabular}{llll}
\hline Clinical factors & Patients (\%) & Death & Log-rank test, $\mathrm{p}$ \\
\hline Age & & & \\
$>=65$ & $24(53.3 \%)$ & 14 & 0.70 \\
$<65$ & $21(46.7 \%)$ & 9 & \\
Gender & & & \\
Male & $13(28.9 \%)$ & 7 & 0.6 \\
Female & $32(71.1 \%)$ & 16 & \\
Race & & & \\
Asian & $2(4.4 \%)$ & 1 & 0.6 \\
Black or African American & $3(6.7 \%)$ & 1 & \\
Not reported & $4(8.9 \%)$ & 1 & \\
White & $36(80.0 \%)$ & 20 & \\
Cancer Status & & & \\
Tumor free & $20(44.4 \%)$ & 6 & \\
With tumor & $15(33.3 \%)$ & 12 & \\
Unknow & $10(22.2)$ & 5 & \\
Stage & & & \\
Stage I & $22(48.9 \%)$ & 9 & \\
Stage II & $9(20.0 \%)$ & 5 & \\
Stage III & $11(24.4 \%)$ & 8 & \\
Stage IV & $2(4.4 \%)$ & 1 & \\
Not reported & $1(2.2 \%)$ & 0 & \\
\hline
\end{tabular}

(AUC $=0.853)$ well prediction capacity (Fig. 5c). Additionally, RS of RFS was also validated in TCGA database (Fig. 5d). The result of RS in RFS was similar to overall survival $(\mathrm{HR}=5.132,95 \% \mathrm{CI}: 1.531-17.220)$. And the log-rank test showed that these genes could significantly classify patients into two groups $(p=0.0036)$. AUC of RS of RFS also showed well prediction capacity in 3 years $(\mathrm{AUC}=0.746)$.

\section{KEGG pathway enrichment}

The results of pathway enrichment will be able to show how these drugs act on the pathway, thereby alleviating cell resistance to drugs (Fig. 6). Through the result of KEGG pathway enrichment showed that two pathways (hsa05223: Non-small cell lung cancer and hsa01521: EGFR tyrosine kinase inhibitor resistance) were directly associated with EGFR-TKI resistance.

The EGFR tyrosine kinase inhibitor resistance pathway showed that there were many pathways can lead to drug resistance. In this study, the pathway enrichment indicated that FZKA acted on PRKCA and BCL2 pathway to affect drug resistance. In addition, in Non-small cell lung cancer, FZKA also act on PRKCA and CDKN1A (p21).

\section{Molecular docking assay}

The mechanism of FZKA was reflected by interaction of compound and target. Thus, molecular docking simulation is used to analyze interaction between them. Three targets and four compounds which involve in the EGFR-TKI resistance were listed in Table 4.

The versatile functions of CDKN1A (p21) are not fully understood and the associated pathways and mechanism need to be further elucidated (a. Less understood issues: p21Cip1 in mitosis and its therapeutic potential; b. Ironing out the role of the cyclin-dependent kinase inhibitor, p21 in cancer: Novel iron chelating agents to target p21 expression and activity). The structure and the interacting information of active pocket of CDKN1A (p21) are still lacking. Thus, we mainly concentrated our docking analysis on PRKCA and BCL2. The 3D structure of PRKCA and BCL2 are derived from the PDB database and used for docking analysis (Fig. 7).

In simulation processing, CDKN1A (p21) does not have full-length crystal structure and active pocket information. Thus, we searched 3D structure of PRKCA and BCL2 for docking analysis.

PRKCA protein has a common characteristic of kinases and a small-molecule ligand is bound to ATP's competitive pockets [37]. During the molecular docking simulation, we docked beta-sitosterol into the binding pocket of PRKCA protein, however, it returned no binding poses of beta-sitosterol, which indicates that beta-sitosterol doesn't have the ability to bind to the active site of PRKCA protein. The binding pocket of BCL2 shows that it has the characteristics of protein-protein interaction [38]. The results of docking simulation for $\mathrm{BCL} 2$ suggested that all the three small-molecule ligands could be docked to the binding site of BCL2 as shown in Fig. $8 \mathrm{a}, \mathrm{b}$ and c. LCA tends to have the best affinity among three compounds according to the docking scores (Table 5) and the detailed binding mode of LCA was analyzed. As shown in Fig. 8d, e, LCA was buried in a hydrophobic pocket formed by Phe101, Asp108, Phe109, Met112, Glu133, Leu134, Asn140, Arg143, Ala146, Phe150, Val153. Among these residues, the hydroxy of LCA had a hydrogen bonding with Arg143, while the benzene rings of LCA formed $\pi-\pi$ stacking and $\pi$-cation interaction with Phe101 and Arg143. The results of the molecular docking simulation above showed that BCL2 tended to be the potential target involved in EGFR-TKI resistance and non-small cell lung cancer pathways and LCA could be an active compound to decrease the EGFR-TKI resistance.

\section{Discussion}

Recently, with the growing research on CHM by network, a new "multi-target, multi-drug" model was considered as more effective strategy for understanding 

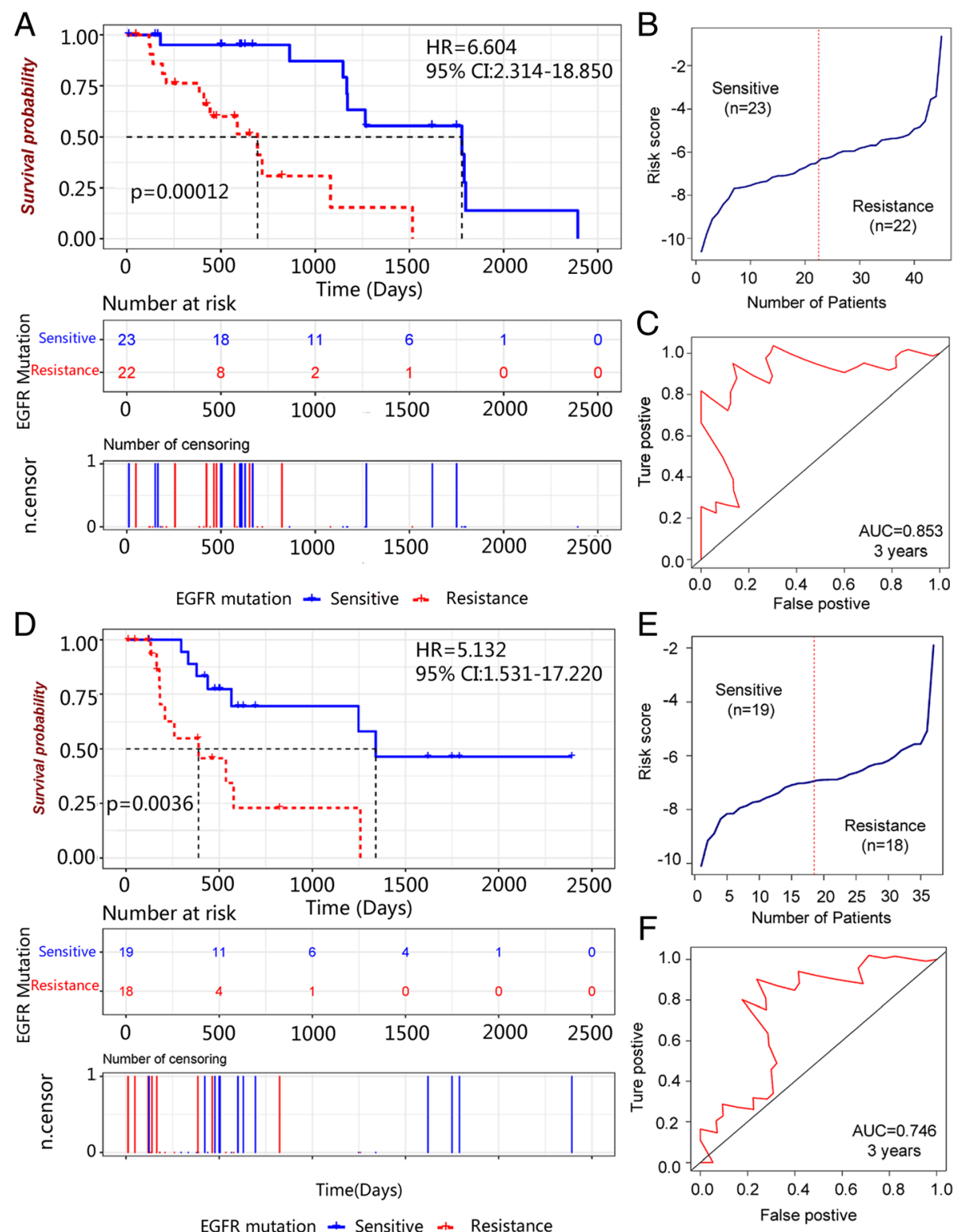

Fig. 5 Core genes prognostic validation in LUAD with EGFR-mutation cohort. a Kaplan-Meier survival curve of sensitive and resistance groups for overall survival. b RS distribution in all mutation patients. c AUC of ROC for predicting RS of OS (AUC =0.853). $\mathbf{d}$ Kaplan-Meier survival curve of sensitive and resistance groups for disease free survival. e RS distribution in all mutation patients with disease free survival information. $\mathbf{f}$ AUC of ROC for predicting RS of DFS (AUC $=0.746)$

drug action and treatment complex disease [39]. Although a CHM formulation of FZKA was reported for treatment NSCLC patients with EGFR-TKI resistance, the mechanism o formulations have not been illustrated. In this work, we employed complex network analysis, bioinformatics and computer simulation methods for investigating the mechanism of drug action. The results suggested that one of the main mechanisms may be by inhibiting BCL2 and PRKCA pathway which were EGFR-TKI resistance pathways for overcoming EGFR-TKI resistance.
Generally, many studies considered that hub targets or hub pathways interacted with compounds in the network as an important point in drug action. In this study, ADRB2 is a hub node in the subnetwork. The subnetwork showed that there were many molecules interacting with ADRB2 (Fig. 4c). Beta-2 adrenergic receptor (ADRB2), coded by an intronless gene on chromosome 5q31-32, mediate the catecholamine-induced activation of adenylate cyclase through the action of G proteins [40]. Generally, ADRB2 was reported that it significantly associated development of cancer and it is considered that 


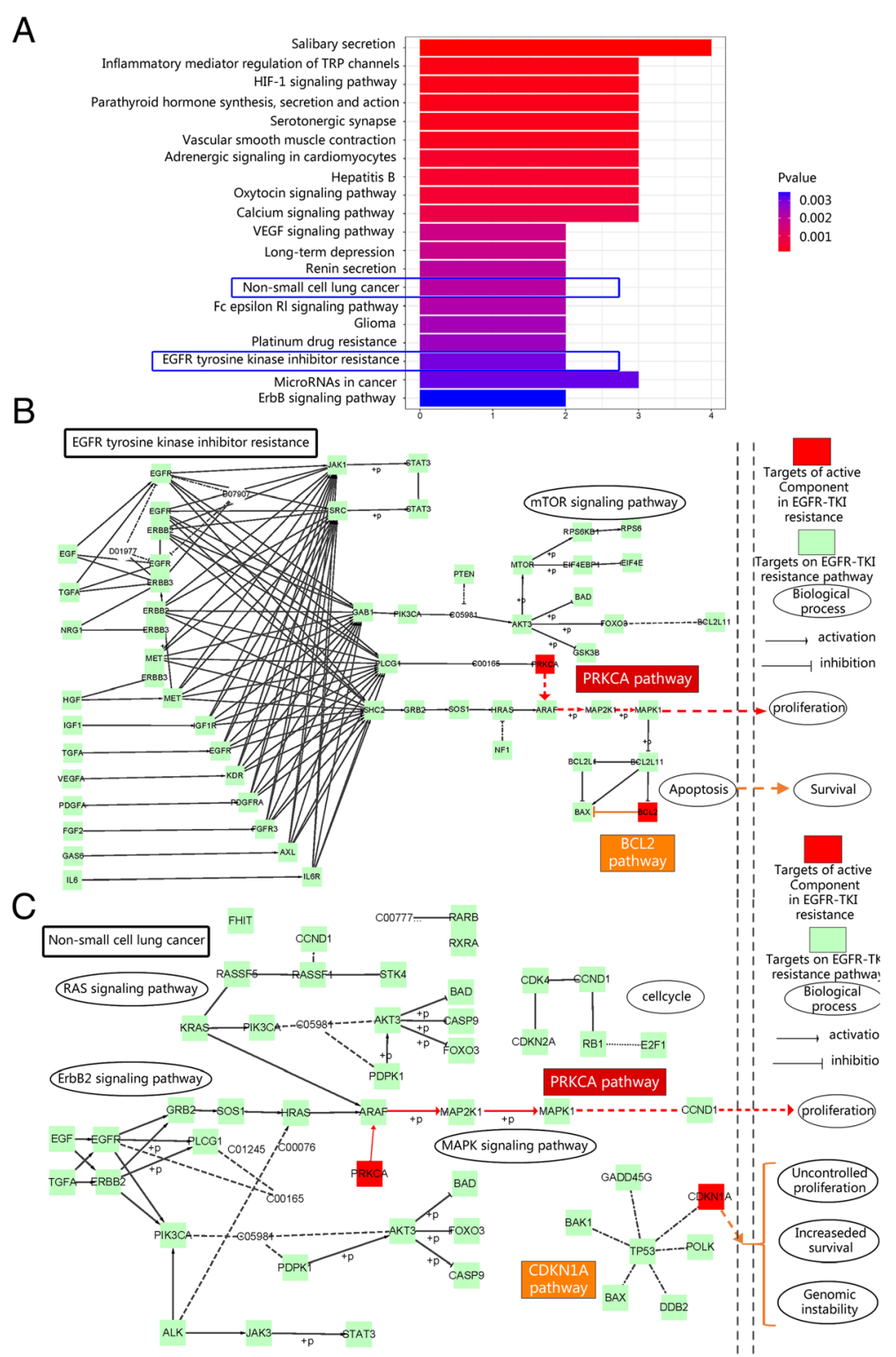

Fig. 6 KEGG enrichment of core genes. a KEGG pathway enrichment of core genes. b. EGFR tyrosine kinase inhibitor resistance pathway. c Non-small cell lung cancer pathway

sympathetic neurotransmitters can act as ligands and activate ADRB2 expressed on the surface of tumor cells to promote tumor growth [41]. In addition, ADRB2 was also found that it associated with risk of asthma and LUAD [42-44]. At present, the relationship between ADRB2 and lung cancer is mainly related to the activation of mitotic pathways [44]. And some studies figure out activity ADRB2 can active EGFR signaling pathway for tumor growth $[45,46]$. Although ADRB2 was not directly involved in EGFR-TKI resistance pathway in this study, the role of ADRB2 was very important in EGFR-TKI resistance due to involve in cell proliferation and EGFR signaling pathway.
The proteins involved in important biological pathways was considered as core proteins. And the compounds interacted with core proteins may be key component in herbs. There eight genes were searched from overlap of targeted proteins and DEG from sensitive and resistance PC9 cell lines. And eight genes can predict prognosis of LUAD patients with EGFR mutation. And RS of these genes can significantly classify the patients into sensitive and resistance groups (Fig. 6).

Of these genes, BCL2, PRKCA (PKC) and CDKN1A (p21) were directly associated with EGFR-TKI resistance pathway (hsa01521) and NSCLC pathway (hsa05223). And five compounds act on these proteins (Table 5). 
Table 4 The genes involved in two pathways for molecular docking

\begin{tabular}{lllll}
\hline Molecular ID & Molecular names & Protein name & Uniprot ID & Gene symbol \\
\hline MOL000358 & beta-sitosterol & Protein kinase C alpha type & P17252 & PRKCA \\
MOL000358 & beta-sitosterol & Apoptosis regulator BCl-2 & P10415 & BCL2 \\
MOL000546 & diosgenin & Cyclin-dependent kinase inhibitor1 & P38936 & CDKN1A \\
MOL002773 & beta-carotene & Apoptosis regulator BCl-2 & P10415 & BCL2 \\
MOL000491 & licochalcone a & Apoptosis regulator BCl-2 & P10415 & BCL2 \\
\hline
\end{tabular}

BCL2 is a noted protein in regulation apoptosis of cancer. Previous study reported that overexpression BCL2 can inhibit apoptosis in cancer cells [47]. And BCL2 was also reported that it involved in the mediation of chemotherapy resistance in NSCLC [48]. In this study, EGFR-TKI resistance cell lines have high expression of BCL2 (Fig. 4b). In addition, the results showed that three compounds acted with BCL2. And licochalcone a (LCA) showed the best score in three compounds. According to previous study, LCA can inhibit BCL2 for inducing autophagy and promoting apoptosis in cancer cells [49]. Another study reported that LCA induced autophagy effect in NSCLC cells [50]. Although these two studies reported that LCA can induce apoptosis and autophagy by experiment, the mechanism of molecular level has not been revealed. In our study, the simulation results showed that LCA act on active package of BCL2 protein. The binding of small molecules to BCL2 can influence the binding of BCL to downstream ligands. Therefore, the binding of three small molecules and BCL2 may play vital role in regulation apoptosis of LUAD with EGFR-TKI resistance.

Other two proteins (PRKCA and CDKN1A) were also analyzed in study. But 3D structure of CDKN1A(p21) has not been resolved yet. So, the mechanism of CDKN1A fail to analyze. Additionally, in analysis of PRKCA, the binding of beta-sitosterol and PRKCA was very different from common PRKCA inhibitor. So, the molecular simulation software doesn't get the result from PRKCA. Although PRKCA and CDKN1A have not been validation by molecular simulation, the results also indicated that FZKA could overcome EGFR-TKI resistance through affecting eight core targets. Of these targets, ADRB2, BCL2, PRKCA and CDKN1A were reported by previous publications. Other genes have not been reported to associated with EGFR-TKI in LUAD.

Above all, from our analysis, the compounds from Hedyotis Diffusae Herba, licorice, Hedysarum multijugum Maxim, Solanum nigrum Linn, Curcumae Rhizoma and Atractylodes Macrocephala Koidz play major role in overcoming EGFR-TKI resistance in LUAD. And BCL2 and PKC pathways may be main targets of FZKA. And these two targets as drug targets for overcoming EGFR-TKI resistance were also reported by previous publication. Other targets such as LYZ, HTR2C, KCNMA1 and PLA2G4A were not enriched in pathway that related with EGFR-TKI resistance. However, these targets may be potential
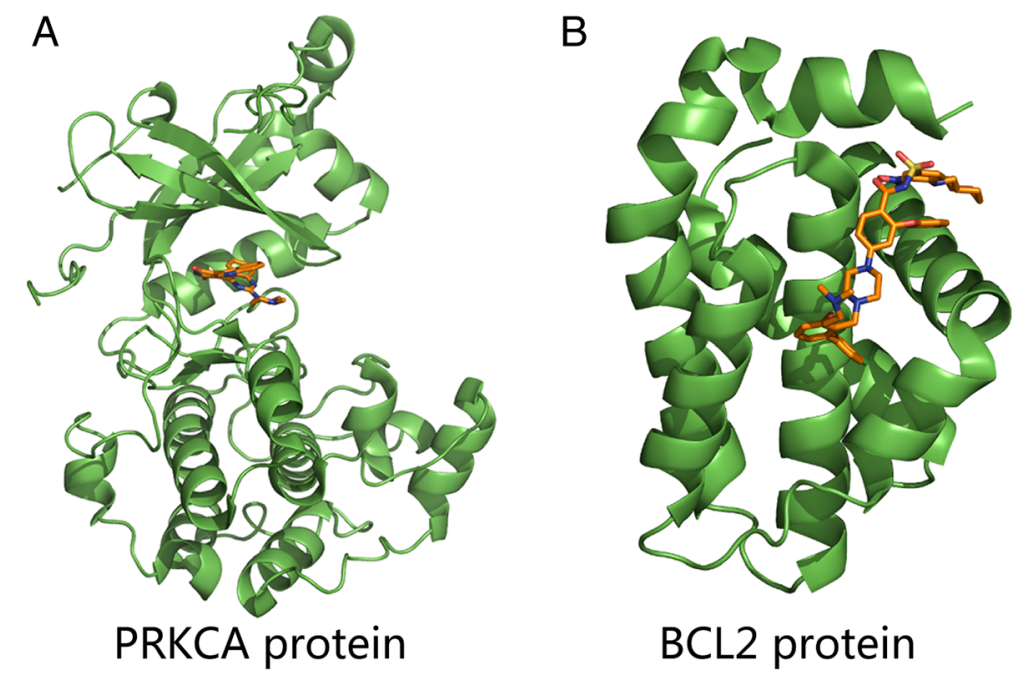

Fig. 7 The binding sites of PRKCA and BCL2. a Three-dimension structure of PRKCA. $\mathbf{b}$ Three-dimension structures of BCL2. The proteins are shown in green cartoon and the co-crystalized inhibitors are shown in orange sticks 


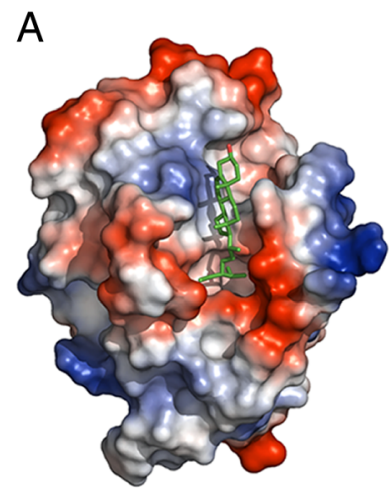

beta-sitosterol act on BCL2

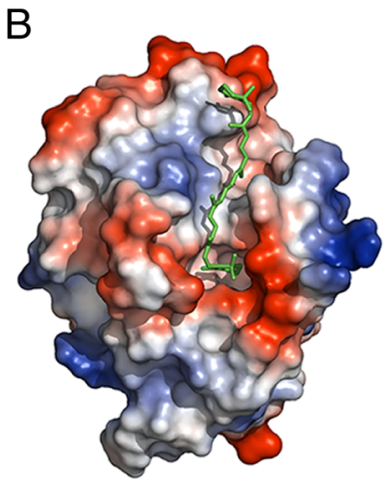

beta-carotene act on BCL2

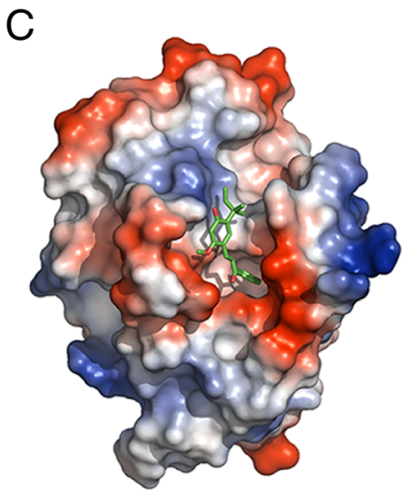

licochalcone a act on BCL2

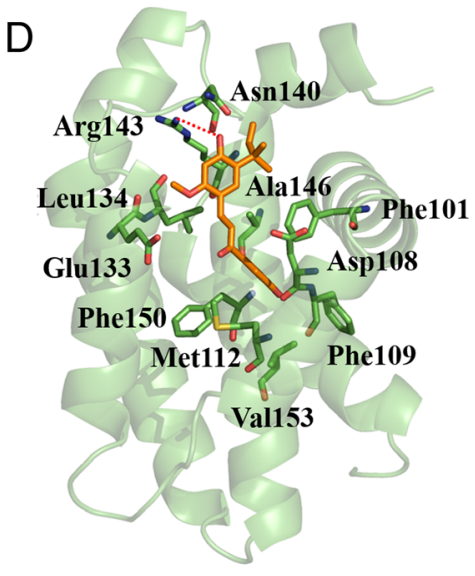

The binding site of licochalcone a

$\mathrm{E}$

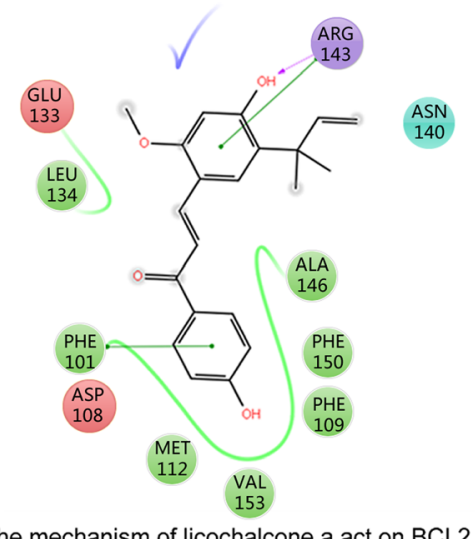

Fig. 8 The interactive modes of beta-sitosterol, beta-carotene, licochalcone a with BCL2. a beta-sitosterol binding on the pocket of BCL2. $\mathbf{b}$ betacarotene binding on the pocket of BCL2. $\mathbf{c}$ licochalcone a binding on the pocket of BCL2. $\mathbf{d}$ the three-dimensional representation of the binding mode of licochalcone a with BCL2. The residues in the binding site are shown in green sticks and licochalcone a is shown in orange sticks. e the electrical characteristics of the surrounding residues of licochalcone a and the interaction between licochalcone a and BCL2. The green, cyan, red, blue circles represent hydrophobic, polar, negative-charged, positive-charged residues

targets of drug resistance. Further experiments are still needed confirm this conclusion.

\section{Conclusion}

In clinical practice, it has been found that FZKA has the effect of overcoming the drug resistance of EGFR mutations positive, but the molecular mechanism is unclear. This study revealed that compounds from FZKA directly acted on targets which involved in EGFR-TKI resistance. That interaction indicated that FZKA can overcome drug resistance through inhibiting BLC2 and PRKCA pathways.

Table 5 SP- and XP-Docking score of three compounds

\begin{tabular}{llll}
\hline Molecular ID & Compound name & SP-docking & XP-docking \\
\hline MOL000358 & beta-sitosterol & -4.446 & -4.542 \\
MOL000546 & beta-carotene & -3.845 & -4.925 \\
MOL000497 & licochalcone a & -5.339 & -5.312 \\
\hline
\end{tabular}

\section{Additional files}

Additional file 1: The details information of 76 compounds that were filtered by ADME from the eleven herbs of FZKA. (XLSX 16 kb)

Additional file 2: The compound-target network was consisted by 76 compounds and 130 targets. (XLSX $14 \mathrm{~kb}$ )

Additional file 3: The information of compound-pathway network obtained with network analysis. (XLSX $16 \mathrm{~kb}$ )

\section{Abbreviations}

ADME: Absorption, distribution, metabolism and excretion; AUC: Area Under roc Curve; CHM: Chinese herbs medicine; DEGs: Differential gene expressions; DL: Drug-likeness; EGFR: Epidermal growth factor receptor; EGFR-

TKI: Epidermal growth factor receptor tyrosine kinase inhibitors; FZKA: Fuzhengkangai; KEGG: Kyoto Encyclopedia of Genes and Genomes; LCA: Licochalcone a; LUAD: Lung adenocarcinoma; NSCLC: Non-small cell lung cancer; OB: Oral bioavailability; ROC: Receiver Operating Characteristic; RS: Risk score

\section{Acknowledgements}

We gratefully acknowledge the support of Institute of modern physics, Chinese Academic of science, with the donation of the P100 GPU (NVIDIA Corporation) used for our simulations. 


\section{Funding}

This work was supported by Gansu province funding (No. 1606RJZA016).

This funding has supported the data analysis and design of the study in this work

\section{Availability of data and materials}

We have presented all our main data in the form of tables in additional file. The datasets supporting the conclusions of this article are available in public database from TCMSP, PDB database, TCGA and GEO (GSE34228) dataset.

\section{Authors' contributions}

$\mathrm{KY}$ and $\mathrm{YW}$ formulated the idea of the paper and supervised the research. ZB and ZC performed the research, analyzed the data and wrote the manuscript. DS and XL designed molecular docking by computer. JX and JZ computed the clinical variable in Table 3 and analyzed the prognostic core genes in EGFR mutation LUAD cohort. XY participated in revising the data and improving manuscript writing. All authors reviewed the manuscript. And all authors read and approved the final version of the manuscript.

\section{Ethics approval and consent to participate}

Not applicable.

\section{Consent for publication}

Not applicable.

\section{Competing interests}

The authors declare that they have no competing interests.

\section{Publisher's Note}

Springer Nature remains neutral with regard to jurisdictional claims in published maps and institutional affiliations.

\section{Author details}

${ }^{1}$ Evidence Based Medicine Center, School of Basic Medical Science of Lanzhou University, Lanzhou, China. ${ }^{2}$ Key Laboratory of Evidence Based Medicine and Knowledge Translation of Gansu Province, 199 West Donggang Road, Lanzhou 730000, Gansu, China. ${ }^{3}$ Institute of Modern Physics of Chinese Academy of Sciences, Lanzhou, Gansu Province, China. ${ }^{4}$ Department of Chemistry, State Key Laboratory of Applied Organic Chemistry, Lanzhou University, Lanzhou, China. ${ }^{5}$ Department of Clinical Chinese Pharmacy, School of Chinese Materia Medica, Beijing University of Chinese Medicine, Beijing, China. ${ }^{6}$ Gansu University of Chinese Medicine, Lanzhou, China.

\section{Received: 2 August 2018 Accepted: 9 October 2018}

\section{Published online: 06 November 2018}

\section{References}

1. Morosibilot D, Audigiervalette C, Merle P, Quoix E, Souquet PJ, Barlesi F, Chouaid C, Molinier O, Bennouna J, Lavolé A. Non-small cell lung cancer recurrence following surgery and perioperative chemotherapy: comparison of two chemotherapy regimens (IFCT-0702: a randomized phase 3 final results study). Lung Cancer. 2015;89(2):139-45.

2. Dong JK, Lei HM, Liang Q, Tang YB, Zhou Y, Wang Y, Zhang S, Li WB, Tong $Y$, Zhuang G. Overcoming erlotinib resistance in EGFR mutation-positive lung adenocarcinomas through repression of phosphoglycerate dehydrogenase. Theranostics. 2018;8(7):1808-23.

3. Chen W, Zheng R, Baade PD, Zhang S, Zeng H, Bray F, Jemal A, Yu XQ, He J. Cancer statistics in China, 2015. CA Cancer J Clin. 2016;66(2):115-32.

4. Mendelsohn J, Baselga J. Status of epidermal growth factor receptor antagonists in the biology and treatment of Cancer. J Clin Oncol. 2003;21(14):2787.

5. Zhou C, Wu Y, Chen G, Feng J, Liu X, Wang C, Zhang S, Wang J, Zhou S, Ren $S$, et al. Erlotinib versus chemotherapy as first-line treatment for patients with advanced EGFR mutation-positive non-small-cell lung cancer (OPTIMAL, CTONG-0802): a multicentre, open-label, randomised, phase 3 study. Lancet Oncol. 2011;12(8):710-1.

6. Kobayashi S, Boggon TJ, Dayaram T, Jänne PA, Kocher O, Meyerson M, Johnson BE, Eck MJ, Tenen DG, Halmos B. EGFR mutation and resistance of non-small-cell lung cancer to gefitinib. N Engl J Med. 2005;352(8):786-92.
7. Pao W, Miller VA, Politi KA, Riely GJ, Somwar R, Zakowski MF, Kris MG, Varmus $\mathrm{H}$. Acquired resistance of lung adenocarcinomas to Gefitinib or Erlotinib is associated with a second mutation in the EGFR kinase domain. PLoS Med. 2005;2(3):225-35.

8. MF Z, M L MGK. EGFR mutations in small-cell lung cancers in patients who have never smoked. N Engl J Med. 2006;355(2):213.

9. Sequist LV, Waltman BA, Diassantagata D, Digumarthy $S$, Turke AB, Fidias $P$, Bergethon K, Shaw AT, Gettinger S, Cosper AK. Genotypic and histological evolution of lung cancers acquiring resistance to EGFR inhibitors. Sci Transl Med. 2011;3(75):75ra26.

10. Xie M, Zhang L, He CS, Xu F, Liu JL, Hu ZH, Zhao LP, Tian Y. Activation of Notch-1 enhances epithelial-mesenchymal transition in gefitinib-acquired resistant lung cancer cells. J Cell Biochem. 2012;113(5):1501-13.

11. Zhang Z, Lee JC, Lin L, Olivas V, Au V, Laframboise T, Abdelrahman M, Wang $X$, Levine AD, Rho JK. Activation of the AXL kinase causes resistance to EGFR-targeted therapy in lung cancer. Nat Genet. 2012;44(8):852.

12. Bean J, Brennan C, Shih JY, Riely G, Viale A, Wang L, Chitale D, Motoi N, Szoke J, Broderick S. MET amplification occurs with or without T790M mutations in EGFR mutant lung tumors with acquired resistance to Gefitinib or Erlotinib. Proc Natl Acad Sci U S A. 2007;104(52):20932-7.

13. Engelman JA, Zejnullahu K, Mitsudomi T, Song Y, Hyland C, Park JO, Lindeman N, Gale CM, Zhao X, Christensen J. MET amplification leads to Gefitinib resistance in lung Cancer by activating ERBB3 signaling. Science. 2007;316(5827):1039-43.

14. Takezawa K, Pirazzoli V, Arcila ME, Nebhan CA, Song X, De SE, Ohashi K, Janjigian YY, Spitzler PJ, Melnick MA. HER2 amplification: a potential mechanism of acquired resistance to EGFR inhibition in EGFR-mutant lung cancers that lack the second-site EGFRT790M mutation. Cancer Discov. 2012;2(10):922.

15. Ohashi K, Sequist LV, Arcila ME, Moran T, Chmielecki J, Lin YL, Pan Y, Wang L, Stanchina ED, Shien K. Lung cancers with acquired resistance to EGFR inhibitors occasionally harbor BRAF gene mutations but lack mutations in KRAS, NRAS, or MEK1. Proc Natl Acad Sci U S A. 2012;109(31):12282-3.

16. Wu DW, Wu TC, Chen CY, Lee H. PAK1 is a novel therapeutic target in tyrosine kinase inhibitor-resistant lung adenocarcinoma activated by the PI3K/AKT signaling regardless of EGFR mutation. Clin Cancer Res. 2016;22(21):5370-82.

17. Wang $H$, Fei $Z$, Jiang $H$. Polyphyllin VII increases sensitivity to gefitinib by modulating the elevation of P21 in acquired gefitinib resistant non-small cell lung cancer. J Pharmacol Sci. 2017;134(3):190-6.

18. Cheong HT, Xu F, Choy CT, Hui C, Mok T, Wong CH. Upregulation of $\mathrm{BCl} 2$ in NSCLC with acquired resistance to EGFR-TKI. Oncol Lett. 2018;15(1):901-7

19. Guerard M, Robin T, Perron $P$, Hatat AS, David-Boudet $L$, Vanwonterghem $L$, Busser B, Coll JL, Lantuejoul S, Eymin B. Nuclear translocation of IGF1R by intracellular amphiregulin contributes to the resistance of lung tumour cells to EGFR-TKI. Cancer Lett. 2018:420:146-55.

20. Efferth T, Li PC, Konkimalla VS, Kaina B. From traditional Chinese medicine to rational cancer therapy. Trends Mol Med. 2007;13(8):353-61.

21. Duflos A, Kruczynski A, Barret JM. Novel aspects of natural and modified vinca alkaloids. Curr Med Chem Anticancer Agents. 2002;2(1):55-70.

22. Yang XB, Wu WY, Long SQ, Deng $H$, Pan ZQ. Effect of gefitinib plus Chinese herbal medicine $(\mathrm{CHM})$ in patients with advanced non-small-cell lung cancer: a retrospective case-control study. Complement Ther Med. 2014;22(6):1010-8

23. Zeng L, Yang K. Exploring the pharmacological mechanism of Yanghe decoction on HER2-positive breast Cancer by a network pharmacology approach. J Ethnopharmacol. 2017;199(5):68.

24. Zhang RZ, Yu SJ, Bai H, Ning K. TCM-mesh: the database and analytical system for network pharmacology analysis for TCM preparations. Sci Rep. 2017;7(1):2821.

25. Huang J, Cheung F, Tan HY, Hong M, Wang N, Yang J, Feng Y, Zheng Q. Identification of the active compounds and significant pathways of yinchenhao decoction based on network pharmacology. Mol Med Rep. 2017;16(4):4583-92.

26. Ru J, Li P, Wang J, Zhou W, Li B, Huang C, Li P, Guo Z, Tao W, Yang Y. TCMSP: a database of systems pharmacology for drug discovery from herbal medicines. J Cheminform. 2014;6(1):13.

27. Wang X, Xu X, Li Y, Li X, Tao W, Li B, Wang Y, Yang L. Systems pharmacology uncovers Janus functions of botanical drugs: activation of host defense system and inhibition of influenza virus replication. Integr Biol. 2013;5(2):351-71. 
28. Zheng C, Pei T, Chao H, Chen X, Bai Y, Xue J, Wu Z, Mu J, Yan L, Wang Y. A novel systems pharmacology platform to dissect action mechanisms of traditional Chinese medicines for bovine viral diarrhea disease. Eur J Pharm Sci. 2016;94:33-45.

29. Pei T, Zheng C, Huang C, Chen X, Guo Z, Fu Y, Liu J, Wang Y. Systematic understanding the mechanisms of vitiligo pathogenesis and its treatment by Qubaibabuqi formula. J Ethnopharmacol. 2016;190:272-87.

30. Liu J, Pei T, Mu J, Zheng C, Chen X, Chao H, Fu Y, Liang Z, Wang Y. Systems pharmacology uncovers the multiple mechanisms of Xijiao Dihuang decoction for the treatment of viral hemorrhagic fever. Evid Based Complement Alternat Med. 2016;2016(6):1-17.

31. Li L, Li Y, Wang Y, Zhang S, Yang L. Prediction of human intestinal absorption based on molecular indices. J Mol Sci. 2007;23(4):286-91.

32. Tao W, Xu X, Wang X, Li B, Wang Y, Li Y, Yang L. Network pharmacologybased prediction of the active ingredients and potential targets of Chinese herbal Radix Curcumae formula for application to cardiovascular disease. J Ethnopharmacol. 2013;145(1):1-10.

33. Kassambara A: survminer: Drawing Survival Curves using 'ggplot2'. 2016.

34. Heagerty PJ, Pepe MS: Time-Dependent ROC Curves for Censored Survival Data and a Diagnostic Marker; 2000

35. Smoot ME, Ono K, Ruscheinski J, Wang PL, Ideker T. Cytoscape 2.8: new features for data integration and network visualization. Bioinformatics. 2011;27(3):431-2.

36. Yu G, Wang LG, Han Y, He QY. clusterProfiler: an R package for comparing biological themes among gene clusters. OMICS. 2012;16(5):284-7.

37. Wagner J, Matt PV, Sedrani R, Albert R, Cooke N, Ehrhardt C, Geiser M, Rummel G, Stark W, Strauss A. Discovery of 3-(1H-Indol-3-yl)-4-[2-(4methylpiperazin-1-yl)quinazolin-4-yl]pyrrole-2,5-dione (AEB071), a potent and selective inhibitor of protein kinase C isotypes. J Med Chem. 2009;52(20):6193-6.

38. Souers AJ, Leverson JD, Boghaert ER, Ackler SL, Catron ND, Chen J, Dayton BD, Ding H, Enschede SH, Fairbrother WJ. ABT-199, a potent and selective BCL-2 inhibitor, achieves antitumor activity while sparing platelets. Nat Med. 2013;19(2):202-8.

39. Hopkins AL. Network pharmacology. Nat Biotechnol. 2007;25(10):1110.

40. Green SA, Turki J, Innis M, Liggett SB. Amino-terminal polymorphisms of the human $\beta 2$-adrenergic receptor impart distinct agonist-promoted regulatory properties. Biochem. 1994;33(32):9414-9.

41. Palm D, Lang K, Niggemann B, Th DT, Masur K, Zaenker KS, Entschladen F. The norepinephrine-driven metastasis development of $\mathrm{PC}-3$ human prostate cancer cells in BALB/C nude mice is inhibited by beta-blockers. Int J Cancer. 2010;118(11):2744-9.

42. Liang SQ, Chen XL, Deng JM, Wei X, Gong C, Chen ZR, Wang ZB. Beta-2 adrenergic receptor (ADRB2) gene polymorphisms and the risk of asthma: a meta-analysis of case-control studies. PLoS One. 2014;9(8):e104488.

43. Kim SH, Ye YM, Hur GY, Lee HY, Jee YK, Lee SH, Holloway JW, Park HS. Effect of $\beta 2$-adrenergic receptor polymorphism in asthma control of patients receiving combination treatment. Yonsei Med J. 2009;50(2):182.

44. Wang H, Hao B, Chen X, Zhao N, Cheng G, Jiang Y, Liu Y, Lin C, Tan W, Lu D. Beta-2 adrenergic receptor gene (ADRB2) polymorphism and risk for lung adenocarcinoma: a case-control study in a Chinese population. Cancer Lett. 2006;240(2):297-305.

45. He Z, Zhang S. Egfr activation results in enhanced expression of Cox-2 and tumor growth through Adrb2 in Escc. J Gastroenterol Hepatol. 2013;28:855.

46. Li J, Yang X-M, Wang Y-H, Feng M-X, Liu X-J, Zhang Y-L, Huang S, Wu Z, Xue F, Qin W-X. Monoamine oxidase a suppresses hepatocellular carcinoma metastasis by inhibiting the adrenergic system and its transactivation of EGFR signaling. J Hepatol. 2014;60(6):1225-34.

47. Raffo AJ, Perlman H, Chen MW, Day ML, Streitman JS, Buttyan R. Overexpression of bcl-2 protects prostate cancer cells from apoptosis in vitro and confers resistance to androgen depletion in vivo. Cancer Res. 1995;55(19):4438-45.

48. Sartorius $\cup \mathrm{A}$, Krammer $\mathrm{PH}$. Upregulation of $\mathrm{BCl}-2$ is involved in the mediation of chemotherapy resistance in human small cell lung cancer cell lines. Int J Cancer. 2002;97(5):584-92.

49. Yo YT, Shieh GS, Hsu KF. Licorice and Licochalcone-a induce autophagy in LNCaP prostate Cancer cells by suppression of $\mathrm{BCl}-2$ expression and the mTOR pathway. J Agric Food Chem. 2009;57(18):8266-73.

50. Zhenghai Tang CX, Wang Z, Chai K, Wang Y, Xu X, Wang X, Lu J, Wang Y, Chen $X$, et al. Induction of C/EBP homologous protein-mediated apoptosis and autophagy by licochalcone a in non-small cell lung cancer cells. Sci Rep. 2016;6:26241.

Ready to submit your research? Choose BMC and benefit from:

- fast, convenient online submission

- thorough peer review by experienced researchers in your field

- rapid publication on acceptance

- support for research data, including large and complex data types

- gold Open Access which fosters wider collaboration and increased citations

- maximum visibility for your research: over $100 \mathrm{M}$ website views per year

At BMC, research is always in progress.

Learn more biomedcentral.com/submissions 